\title{
Phytoalexin Accumulations in the Callus Culture of Two Eggplant Genotypes by using Verticillium dahliae Kleb. Elicitor
}

\author{
Sevinç KIRAN ${ }^{1}$, Ş. Şebnem ELLİALTIOĞLU ${ }^{2}$, A. Sülün ÜSTÜN ${ }^{3}$ \\ Ülkü MEHMETOĞLU ${ }^{4}$, Harun BAYRAKTAR ${ }^{5}$, F. Sara DOLAR ${ }^{5}$ \\ ${ }^{1}$ Soil, Fertilizer and Water Resources, Central Research Institute, Ankara, Turkey \\ ${ }^{2}$ Department of Horticulture, Faculty of Agriculture, Ankara University, Ankara, Turkey \\ ${ }^{3}$ Department of Biology, Faculty of Science, Ankara University, Ankara, Turkey \\ ${ }^{4}$ Department of Chemical Engineering, Faculty of Engineering, Ankara University, Ankara, Turkey \\ ${ }^{5}$ Plant Protection Department, Faculty of Agriculture, Ankara University, Ankara, Turkey
}

*Corresponding Author: Ş. Şebnem ELLİALTIOĞLU, Department of Horticulture, Faculty of Agriculture, Ankara University, Ankara, Turkey

\begin{abstract}
In this study, the phytoalexin accumulation in plant tissues was investigated using the callus culture technique in eggplants with the treatments a Verticillium dahliae elicitor. For this purpose, one susceptible cultivar Solanum melongena L. cv. Long Purple and one resistant wild species S. sisymbriifolium to Verticillium wilt were used as the plant materials. Elicitors were applied to the calluses obtained from the hypocotyl explants of both the species. Autoclaved spore suspensions of $V$. dahliae were used as the elicitor. The elicitation was stopped at 24, 48, and $72 \mathrm{~h}$ after the elicitor application. The callus extracts were analyzed by gas-liquid chromatography. The $V$. dahliae elicitor was induced by a solavetivone phytoalexin accumulation in the eggplant callus tissues under in vitro conditions. The highest accumulations were obtained from a '2.0 $\mathrm{mL} \mathrm{V}$. dahliae $\times 72 \mathrm{~h}$ after elicitation' treatment and the 'dose $\times$ time after elicitation' interactions were found to be statistically significant. At the highest $V$. dahliae elicitor application dosage, the amount of solavetivone in the callus cultures of the resistant species was higher than the amount in the susceptible cultivar. The phytoalexins could be very effective in the resistance metabolism of eggplants against to V. dahliae.
\end{abstract}

Keywords: Eggplant, Phytoalexin, Callus culture, Verticillium dahliae, Resistance.

\section{INTRODUCTION}

Turkey is the 5th largest producing country of eggplant after China, India, Egypt, and Iran, with approximately 850.000 tons of eggplant produced annually (FAO 2015). The protected cultivation of eggplant accounts for $20 \%$ of the total eggplant production in Turkey. Commercial production of eggplant is limited by soil-borne diseases, one of which is Verticillium wilt, caused by Verticillium dahlia Kleb. It is estimated that about $20 \%$ of the Turkish eggplant crop is affected by its disease (Saydam and Çöpçü 1973, Kirbag and Turan 2006). In the districts of Antalya, the average prevalence rates of the Fusarium and Verticillium wilting diseases were detected about 20\%. While the prevalence rate of the Fusarium is about 35\% in Mersin, Verticillium was under 5\% (Altınok et al. 2012). Some years, if weather conditions are favourable for Verticillium development, a major reduction in the yield or quality may occur in the open field or greenhouse areas.

Verticillium is one of the most destructive and serious diseases of eggplant. Once the Verticillium fungus is introduced into a field or greenhouse, it can survive for several years in the soil. The combined effect of irrigation and Verticillium wilt infection significantly reduces the early and total production of eggplant and decreases its quality (Bletsos et al. 1999).

Verticillium wilt is caused by the soil-borne fungus Verticillium dahliae (V. dahliae) and the Verticillium fungi are difficult to control (Zhang et al. 2012). Their ability to survive in the soil for long periods with or without a host plant and the colonization of the water-conducting tissues within a plant, limit any scheme to eradicate the pathogens. According to Karademir et al. (2010) the new cultivars are not immune to the Verticillium wilt pathogen and their resistance is indicated by reduced disease incidence and reduced disease severity. Prevention of the disease and the use of resistant 
varieties or cultivars, using the resistant rootstocks are perhaps the best methods for controlling Verticillium wilt (Başay et al. 2011).

The response of different eggplant cultivars to Verticillium wilt is variable. Neshev et al. (1997) determined the response of 37 eggplant cultivars to Verticillium wilt fungus. After natural infection, they calculated the injury index of the plants. About $35 \%$ of the cultivars turned out to be highly resistant and 54\% were slightly susceptible. Daunay et al. (2000) stated that a resistance source in $S$. melongena germplasm against $V$. dahliae is yet to be found and indicated the importance of wild Solanum relatives. They also stated that the resistant genes could be determined by certain markers and that these genes could be used in transgenic plant technology.

Induced resistance offers opportunities for biocontrol. The production of low-molecular antimicrobials stress metabolites, known as phytoalexins, is a good response of plants to infection by microorganisms (González-Lamothe et al. 2009, Iriti and Faoro 2009). Phytoalexins are known to be extremely effective on the subject of resistance formed against disease in plants. The biosynthesis of phytoalexins is believed to be one of the major defensive systems of higher plants.

The production of sesquiterpenoid phytoalexin capsidiol by peppers (Stoessl et al.1972, Üstün 1990) and tobacco (Chappel et al.1987) in response to inoculation with variety of fungi has been described previously. Rishitin (Tomiyama et al. 1968), phytuberin (Varns et al. 1971), and lubimin (Metlitskii et al. 1971) are the sesquiterpenoid phytoalexins from potatoes, and rishitin is also (Tjamos and Smith 1974, Ahmed et al. 1997) produced in tomatoes. Solavetivone has been described from Hyoscyamus muticus (Ramakrishna et al. 1993, Mehmetoğlu and Curtis 1997). Ward et al. (1975) obtained sesquiterpenoid phytoalexins, especially in the lubimin from the infected fruits of eggplant. Sesquiterpenoid phytoalexins and their structures have also been reported in eggplant by Stoessl et al. (1975). Emmanouil and Wood (1981) found some biochemical compounds in S.melongena roots following inoculation with V.dahliae or treatment with benzimidazole fungicides. One sesquiterpenoid, lubimin, was identified. Imoto and Ohta (1988) described the production of diacetylenic compounds in the cultured cells of eggplant upon treatment with abiotic elicitor. Yoshihara et al. (1988) identified by IR, NMR and GC-MS, three sesquiterpenes: solavetivone, lubimin and epilubimin from the roots of S.melongena. Phytoalexins in eggplant include lubimin, aubergenone, 9-oxonerolidol and some other hydronerolidoles reported by Kuc (1992). Five known sesquiterpenoids, solavetivone, lubimin, lubiminoic acid, aethione, and lubiminol, were isolated from the root exudates recovered from S. aethiopicum (Nagaoka et al.2001). Another sesquiterpenoid, described as 3-beta-acetoxysolavetivone, was formed in the roots of Solanum abutiloides plants, which are highly resistant to soil-borne pathogens, such as Fusarium oxysporum f. sp. melongenae, $V$. dahliae, and Ralstonia solanacearum (Yokose et al. 2004).

There is limited information available on elicitors of antifungal compounds in Verticillium diseases (Pegg and Brady 2002). There are some researches on the induced resistance of several plants by using V.albo-atrum elicitor but V.dahliae is rare. Induction of resistance to Flocco et al. (1998) detected an increase with maximum capacity of PO activity in cell cultures of horseradish, when they used Verticillium including elicitor and some other abiotic elicitors.

In recent years, tissue culture techniques have facilitated experimental research to a great extent, have made it more reliable, and have provided the opportunity of working with uniform materials under controlled conditions. Some studies have been made on the subject of the mutual influence of 'resistance to fungal diseases - phytoalexin accumulation' and useful conclusions have been drawn (Kroon and Elgersma 1993, Hoshino et al. 1994, Duchense et al. 1994, Sbaghi et al. 1995, Gardner et al. 1994, Ellialtığlu et al. 2001).

In this research we aimed to have some information about: a) the accumulation of the phytoalexins in the eggplant genotypes (susceptible cultivar and resistant species) by eliciting V.dahliae biotic elicitor, b) Elicitation time and dose of V.dahliae spore suspension elicitor under in vitro conditions, c) Potential of the callus culture system for the detection of genotype resistance and screening studies.

\section{MATERIALS AND METHODS}

It has used one resistant wild eggplant species $S$. sisymbriifolium and one susceptible eggplant cultivar $S$. melongena cv. Long Purple as the plant material. In the previous stage of our studies, the assessments of Verticillium resistance were made using both of these genotypes. As a result of the 
tests carried out by infecting the $V$. dahliae isolate obtained from an infected eggplant in a greenhouse in Antalya (Turkey), the variety of Long Purple was found to be susceptible (60.7\%) and $S$. sisymbriifolium was found to be fully resistant (Üstün et al. 2006) (Fig. 2d).

\subsection{Callus Cultures}

Callus cultures of the eggplant genotypes were initiated. The seeds were surface-sterilized with a $2 \%$ solution of $\mathrm{NaOCl}$ for $10 \mathrm{~min}$, followed by rinsing in 3 changes of sterile water. The sterilized seeds were then placed on MS basal medium (Murashige and Skoog 1962) in Magenta vessels. After 20 days, pieces of hypocotyls $(15-20 \mathrm{~mm})$ were prepared from the in vitro germinated seedlings, and were placed on MS medium supplemented with $1.0 \mathrm{mg}^{-1} 2$, 4-D and $0.1 \mathrm{mg} \mathrm{l}^{-1}$ Kinetin, according to Uslu-Kiran (2004) (Fig 2a). Incubation was at $25 \pm 1{ }^{\circ} \mathrm{C}$ and under darkness continuously. After \pm 3 weeks, callus tissues were grown successfully (Fig. 2b, c) and the original hypocotyl tissue was removed from the callus pieces. The callus cultures were subcultured every 4 weeks and at 2 weeks before the inoculation of the elicitors.

\subsection{Obtaining of Sesquiterpene Standards}

Standard curves of compounds were needed to determine the sesquiterpenoid phytoalexins to the eggplant-calli. For this purpose, first, the slices of potato tubers were elicitated using $0.1 \mathrm{M} \mathrm{CuSO}_{4}$ elicitor for 5 days (Üstün 1990). The method specified by Desjardins et al.(1995) was followed during the elicitation of the potato tubers and the extraction of the phytoalexin compounds from the diffusate solution. Next, the methods explained by Brindle et al. (1983) and Desjardins et al.(1989) were used to obtain the standard curves of the rishitin, lubimin, and solavetivone by thin-layer chromatography (TLC) and gas chromatography (GC). These were shown to have the same TLC (Rf and color reaction) and $\mathrm{GC}(\mathrm{RR} t)$ properties as the 3 sesquiterpenoid phytoalexins of solavetivone [ $\mathrm{R} f 0.44$, buff, RR $t$ (methyl arachidate, 0.56), rishitin (0.21, blue, 0.72) and lubimin (0.28, turquoise, 1.20)] (Fig.2e). Details of the location of the phytoalexins with vanillin- $\mathrm{H}_{2} \mathrm{SO}_{4}$ and the analytical methods were obtained from Brindle et al. (1983).

\subsection{Sesquiterpene Elicitation}

For the elicitation treatments, $2 \mathrm{~g}$ each of callus tissue was transferred to fresh medium in the petri dishes. The callus cultures were incubated under continuous dark conditions at $25 \pm 2{ }^{\circ} \mathrm{C}$ in a growth chamber. The elicitor treatments were carried out on the 14th day of the $3 \mathrm{rd}$ subculture of the eggplant calli, as described previously by Whitehead et al. (1987) for peppers. As the elicitors, autoclaved spore suspensions of $V$. dahliae were used. V.dahliae spores obtained from the Antalya-green hause isolates in our own laboratory (Fig. 2f). The autoclaved spore suspensions of $V$. dahliae were prepared in concentrations of 240, 260, and $480 \mathrm{ppm}$ glucose equivalent and were used as the elicitor. To provide these dosages, $1.0,1.5$, and $2.0 \mathrm{~mL}$ spore solutions were taken and they were dropped onto the surface of each $2 \mathrm{~g}$ callus piece at 24,48 , and $72 \mathrm{~h}$ after treatment, and then the callus tissues were harvested. To obtain the calluses of the control group, no $V$. dahliae suspension treatment was carried out; instead, sterile water in the same amounts was applied. Three replications were carried out for each experiment.

\subsection{Sesquiterpene Analysis}

Extracts were taken from the combined calli comes from each treatment by using diethyl ether, and they were concentrated in a rotoevoporator. The concentrate was redissolved in diethyl ether, filtered, and concentrated to dryness (Fig. $2 \mathrm{~g}$ ). The residue was redissolved in $5 \mathrm{~mL}$ of ethyl acetate, and the sesquiterpenes were analysed by gas-liquid chromatography (GLC) (Hewlett-Packard 5750) fitted with a $30 \mathrm{~m} \mathrm{ZB-1}$ column. All of the technical procedures for the extraction of the sesquiterpenes were performed according to the method of Desjardins et al. (1995). The determination of the phytoalexin amount was calculated as ' $\mu \mathrm{g} \mathrm{g}^{-1}$ fresh mass'. The results of the analyses were compared using the SAS statistical analysis software (SAS Institute, 1990). In all of the experiments described, no phytoalexin could be found in the water treated controls.

\section{RESUlTS AND DisCUSSIONS}

The effects of the $V$. dahliae elicitor on the phytoalexin production in the callus cultures of $S$. melongena cv. Long Purple and S. sisymbriifolium are shown in Figure 1a and 1b. In the calli of the 
Long Purple variety and in the wild species S. sisymbriifolium, solavetivone phytoalexin was determined after 24,48 , or $72 \mathrm{~h}$ of elicitation with the $V$. dahliae elicitor. Phytoalexins are formed in plant tissues by abiotic chemical elicitors (Üstün and Ercoskun 1994) or biotic injection with phytopathogens (Pare et al. 1991). Phytoalexins are pathogen-induced low-molecular weight compounds with antimicrobial activities derived from a secondary metabolism. Although phytoalexines are of very different origin, their antimicrobial effect is in general rather unspecific, and thus efficient against a broad range of pathogens (Großkinsky et al. 2012).

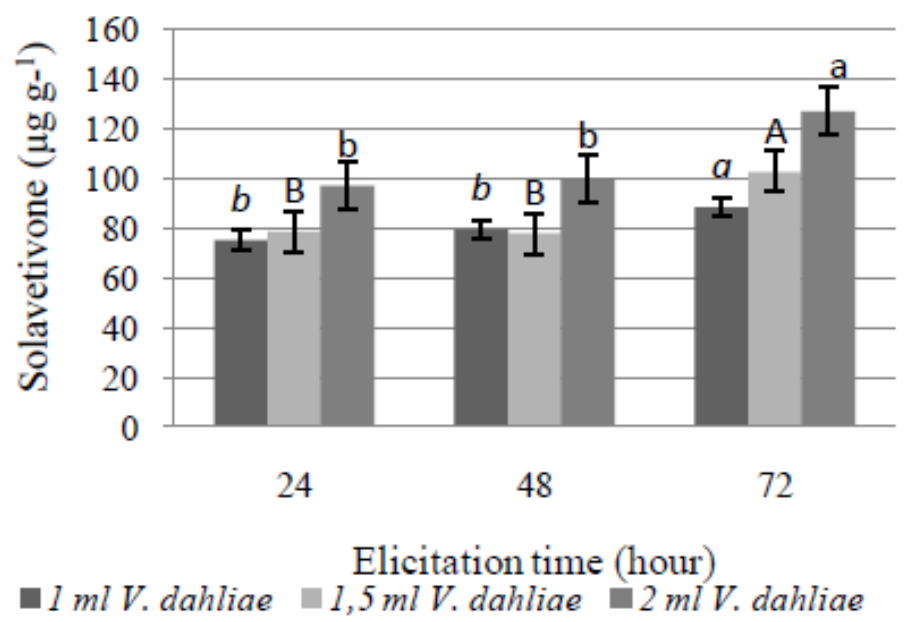

a
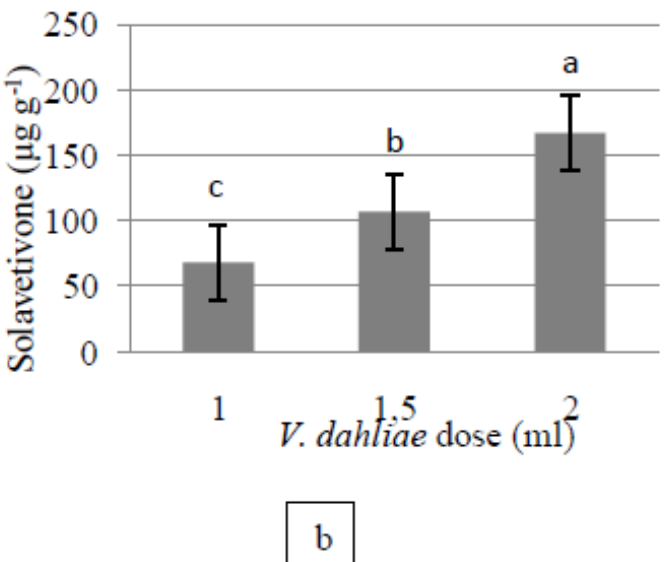

Figure 1.a. Effect of the elicitation dose and the time after elicitation on the solavetivone accumulation in callus cultures of Long Purple cultivar (S. melongena) elicited with autoclaved V. dahliae spore suspension, $b$. Solavetivone accumulation in callus cultures of $S$. sisymbriifolium elicited with autoclaved $V$. dahliae spore suspension 72 hours after elicitation.

Elicitor concentration and duration of elicitor exposure play a very important role in elicitation process (Patel and Krishnamurty 2013). The statistical analyses carried out on the solavetivone amounts varied with the dose and time after elicitation. The triple interaction of the 'Genotype $\times V$. dahliae dose $\times$ Time after elicitation' was found to be statistically significant $(\mathrm{P}<0.01)$. The solavetivone accumulation in the callus cultures increased with the increase in the $V$. dahliae dosage and the time after elicitation. The highest solavetivone accumulation was observed in the Long Purple species at $72 \mathrm{~h}$ after the elicitation in the cultures elicitated with $2.0 \mathrm{~mL}$ of $V$. dahliae spore suspensions $\left(126.67 \pm 1.29 \mu \mathrm{g} \mathrm{g}^{-1}\right)$. Increasing the duration from 24 or 48 to $72 \mathrm{~h}$ increased the accumulation significantly in all of the doses. The autoclaved spore suspension of $V$. dahlia induced 
the phytoalexin accumulation in the callus tissues of the eggplants. The solavetivone formation was obtained from both genotypes. Increases in the time after elicitation and dose of the elicitor positively affected the solavetivone amounts in the calli (Fig. 1). In previously studies, many researchers reported that the fungal elicitors could be used to obtain a phytoalexin formation in different plants (Ward et al. 1975, Üstün et al. 1996, Sbaghi et al. 1995). High dosage of elicitor has been reported to induce hypersensitive response leading to cell death, whereas, an optimum level was required for induction (Namdeo 2004, Patel and Krishnamurty 2013). In a research, cells of C. roseus exposed with several biotic elicitor extracts for $24 \mathrm{~h}, 48 \mathrm{~h}, 72 \mathrm{~h}$ and $96 \mathrm{~h}$. About 2 or 3 -fold increase in ajmalicine production by plant cells elicited with bioelicitors. But increasing exposure time affected the accumulation of the compound negatively (Namdeo and Patil, 2002).

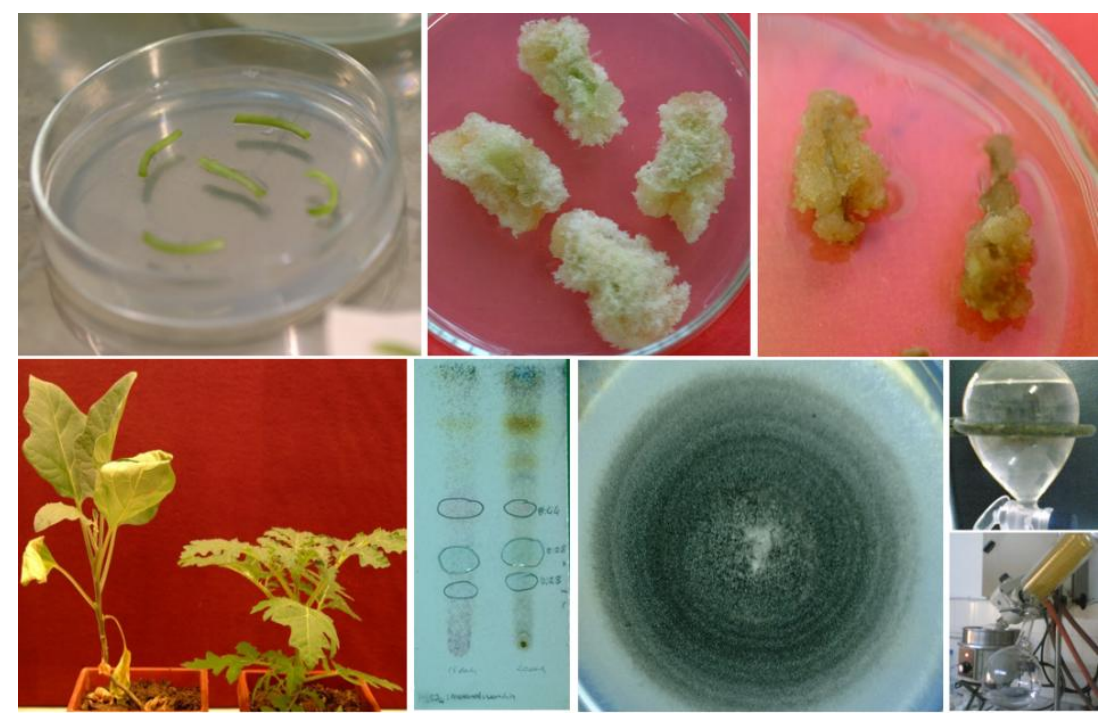

Figure 2.a. Hypocotyl segments as explants of eggplants, b. callus development on the Long Purple eggplant cultivar's explants, $c$. callus development on the explants of S. sisymbriifolium, d. the plants after V.dahliae inoculation, left: $c v$. Long Purple (susceptible), right: S. sisymbriifolium (resistant) (from the previous studies),e. obtaining studies on the standard curves of the rishitin, lubimin, and solavetivone by thin-layer chromatography (TLC), f. V.dahliae cultures from Antalya-greenhouse isolates, g. Studies with rotoevoporator and redissolving stages.

An accumulation was not observed in the wild S. sisymbriifolium calli during the initial 24 and $48 \mathrm{~h}$, possible because the elicitor dose did not have enough stress effect on the resistant species. The measurable accumulations of solavetivone were observed at $72 \mathrm{~h}$ after elicitation. In that application, the highest solavetivone accumulation was observed with the $2.0 \mathrm{~mL}$ elicitation dose $(167.17 \pm 2.04$ $\left.\mu \mathrm{g} \mathrm{g}^{-1}\right)$ and it was followed by the $1.5 \mathrm{~mL}$ elicitation dose $\left(107.50 \pm 0.91 \mu \mathrm{g} \mathrm{g}^{-1}\right)$. Within the same treatment, the amounts of solavetivone accumulated in the $V$. dahliae-resistant $S$. sisymbriifolium calluses were found to be higher than in the culture species. With the application of the V. dahliae elicitor at the highest dose and the longest time after elicitation, the wild species accumulated more phytoalexin than the susceptible variety. Therefore, V. dahliae could be described as a 'good biotic elicitor for determining of resistance $V$. dahliae'. Koike et al. (1992) reported similar results in alfalfa. They applied $V$. albo-atrum culture filtrates to calluses of susceptible and resistance genotypes under in vitro conditions and found that the medicarpin accumulation was higher in the calluses of the resistant genotype than in the susceptible ones.

Solavetivone and related sesquiterpenes have been correlated with the resistance to a number of potato pathogens, including the fungi Phytophthora infestans, which causes late blight (Preisig and Kuc 1987), and Gibberella pulicaris, which causes tuber dry rot (Desjardins and Gardner 1991), and the bacterium Erwinia, which causes blackleg (Abenthum et al. 1995). Desjardins et al. (1997) have reported that there was no correlation between the sesquiterpene levels and the nematode (Globodera rostochiensis) resistance, but the rations of solavetivone to the total sesquiterpenes of the nematodesusceptible and nematode-resistant progeny were significantly different in all of the crosses between resistant and susceptible potato clones. In this study, the solavetivone accumulation in the Long Purple and S. sisymbriifolium callus cultures increased by $126.67 \mu \mathrm{g} \mathrm{g}^{-1}$ and 167.17 with an increasing $V$. dahliae dose, respectively. Similar results were obtained in potato, and it was shown that the levels 
of the phytoalexins rishitin and solavetivone were increased in potato upon pathogen infection when colonized by the mycorrhizal fungus Glomus etunicatum (Yao et al. 2003).

In one of our previous studies, we investigated the phytoalexin accumulation in the 1-month-old fruits of 3 wild species (Solanum sisymbriifolium, S. torvum and S. aethiopicum) and 3 local eggplant varieties (Aydın Siyahı, Kemer, Topan 374) after elicitor treatments under laboratory conditions. The $V$. dahliae spore suspensions as elicitors were prepared as $400 \mathrm{ppm}$ glucose equivalent and autoclaved. After 48 and $96 \mathrm{~h}$ of elicitation, the fruit samples were stored in a deep freezer. The substances that were extracted from fruit tissues were analyzed by GLC. Lubimin was determined in both elicitation times. In general, the lubimin amounts of the wild resistant species were higher than in the cultivated varieties (Sevin et al. 2010). Similar results were obtained from this study and the callus cultures; generally, the phytoalexin accumulation was higher in the wild species than in the eggplant cultivar. According to Großkinsky et al. (2012), phytoalexins can also contribute to the compartmentspecific accumulation of antioxidative activities that is observed during pathogen infections. These results indicate that phytoalexin might be a factor effective in the eggplant resistance to $V$. dahliae fungus. On the other hand, callus or cell suspension cultures could be good systems for investigation the disease resistance mechanism studies. V.dahliae suspensions were observed as an effective biotic elicitor to improve secondary metabolite products in eggplant. To better understand the relationship between phytoalexin accumulation and the resistance to the Verticillium wilt in eggplants, usefulness of this techniques further studies are needed.

\section{REFERENCES}

[1] Abenthum K., Hildenbrandt S. and Ninnemann H., Elicitation and accumulation of phytoalexins in stems, stolons and roots of Erwinia-infected potato plants, Physiol. Mol. Plant Pathol. 46: 349-359 (1995).

[2] Ahmed E.S., El- Essaway A. A., Abou El-Hawa M. E., Ezzat S. M. and Metwaly M. B., Biotic and abiotic initiators for rishitin formation and accumulation in tomato, Folia Microbiol. 42: 468-472 (1997).

[3] Altınok H. H., Boyacı H. F. and Topçu V., Prevalence of Fusarium and Verticillium wilts in greenhouse eggplant production areas of Antalya, Mersin and Samsun provinces and geographical distribution of the virulence of the isolates, Atatürk Univ. J. of the Agricultural Faculty 43 (2): 107-115(2012).

[4] Başay S., Şeniz V. and Tezcan H., Reactions of selected eggplant cultivars and lines to Verticillium wilt caused by Verticillium dahliae kleb., Afr. J. Biotechnol. 10 (18): 3571-3573 (2011).

[5] Bletsos F. A., Thanassoulopoulos C. C. and Roupakias D. G., Water stress and Verticillium wilt severity on eggplant (Solanum melongena L.), J. Phytopathol. 147: 243-248 (1999).

[6] Brindle P.A., Kuhn P.J. and Threlfall D.R. Accumulation of phytoalexins in potato-cell suspension cultures, Phytochem. 22: 2719-2721 (1983).

[7] Chappel R., Nable R., Fleming P., Andersen A.R. and Burton H.R., Accumulation of capsidiol in tobacco cell cultures treated with fungal elicitor, Phytochem. 26: 2259-2260 (1987).

[8] Daunay M.C., Lester R.N., Gebhardt C., Hennart J.W., Jahn M. and Frary A., Genetic resources of eggplant (Solanum melongena) and allied. http://bgard-sci.kund.nl/eggnet/egginfo (2000).

[9] Desjardins A.E., Gardner H.W. and Plattner R.D., Detoxification of the potato phytoalexin lubimin by Giberella pulicaris, Phytochem. 28, 431-437 (1989).

[10] Desjardins A.E. and Gardner H.W., Virulence of Gibberella pulicaris on potato tubers and its relationship to a gene for rishitin metabolism, Phytopathol. 81: 429-435 (1991).

[11] Desjardins A.E., McCormick S.P. and Corsini D.L., Diversity of sesquiterpenes in 46 potato cultivars and breeding selections, J Agr. Food Chem. 43: 2267-2272 (1995).

[12] Desjardins A.E., McCormick S.P., Plaisted R.L. and Brodie B.B., Association between solavetivone production and resistance to Globodera rostochiensis in potato, J Agr. Food Chem. 45: 2322-2326 (1997).

[13] Duchense L.C., Jeng R.S., Hubbes M. and Sticklen M.B., Accumulation of mansonones E and F in elm callus cultures inoculated with Ophiostoma ulmi, Canadian J. Plant Biol. 16: 118-121 (1994).

[14] Ellialtioğlu, Ş., Üstün A.S. and Mehmetoğlu Ü., A research on the relationships between the resistance to root rot and capsidiol accumulation in in vitro callus suspension cultures of peppers. Proceedings of XIth Meetings on Genetics and Breeding of Capsicum and Eggplant, Antalya, Turkey. 34-35 (2001).

[15] Emmanouil V. and Wood R.K.S., Induction of resistance to Verticillium dahliae and synthesis of antifungal compounds in tomato, pepper and eggplant by injecting leaves with various substances, Phytopath. Zeit. 100: 212-225 (1981).

[16] FAO. 2015. FAO (Food and Agriculture Organization), FAO Statistics Database. 
[17] Flocco C.G., Alvarez M.A. and Giuletti A.M., Peroxidase production in vitro by Armoracia lapathifolia (Horseradish)-Transformed root cultures: Effect of elicitation on level and profile of isoenzymes, Biotechnology and Applied Biochemistry 28(1) : 33-38 (1998).

[18] Gardner H.W., Desjardins A.E., McCormick S.P. and Weisleder D., Detoxification of the potato phytoalexin rishitin by Giberella pulicaris, Phytochem.37: 1001-1005 (1994).

[19] González-Lamothe R., Mitchell G., Gattuso M., Diarra M.S., Malouin F. and Bouarab K., Plant antimicrobial agents and their effects on plant and human pathogens, Int. J Mol.Sci. 10: 3400-3419 (2009).

[20] Großkinsky D. K., Van der Graaff E. and Roitsch T., Phytoalexin transgenics in crop protection-Fairy tale with a happy end ?, Plant Sci. 195: 54-70 (2012).

[21] Hoshino T., Chida M., Yamaura T., Yoshizawa Y. and Mizutani J., Phytoalexin induction in green pepper cell cultures treated with arachidonic acid, Phytochem.36: 1417-1419 (1994).

[22] Imoto S. and Ohta Y., Elicitation of diacetylenic compounds in suspension cultured cells of eggplant, Plant Physiol. 86: 176-181 (1988).

[23] Iriti M. and Faoro, F., Chemical diversity and defence metabolism: how plants cope with pathogens and ozone pollution, Int. J Mol. Sci. 10: 3371-3399 (2009).

[24] Karademir E., Karademir C., Ekinci R., Baran B. and Sağır A., Assessment of tolerance level of some cotton (Gossypium hirsutum L.) varieties against Verticillium wilt (Verticillium dahliae Kleb.), Not. Bot. Hort. Agrobot. Cluj. 38(1): 196-202 (2010).

[25] Kirbag S., and Turan N. Fungal agents that cause root and crown rot of some vegetable cultivated in Malatya, Sci. Eng. J. Firat Uni. 18: 159-164 (2006).

[26] Koike M., Saito and J. and Shimada T., Alfalfa - Verticillium albo-atrum interactions: V. Phytoalexin accumulation in calli in response to the cytotoxic components of fungal culture filtrates, Res. Bull. Obihito Uni. Nat. Sci. 18: 35-39 (1992).

[27] Kroon B.A.M. and Elgersma D.M., Interactions between race 2 of Fusarium oxysporum f. sp. lycopersici and near-isogenic resistant and susceptible lines of intact plant or callus of tomato, J. Phytopathol. 137: 17 (1993).

[28] Kuc J., Antifungal compounds from plants. In: Phytochemical Resources for Medicine and Agriculture.1st ed. (eds: Nigg H.N. and D. Seigler). New York, U.S.A.: Plenum Press pp. 159-184 (1992).

[29] Mehmetoğlu U. and Curtis R.W., Effects of abiotic inducers on sesquiterpene synthesis in hair root and cell-suspension cultures of Hyoscya musmuticus, App. Biochem. Biotechnol. 67: 71-77 (1997).

[30] Metlitsk iiL. V., Ozeretskovskaya O.L., Vulfson N.S. and Chalova L.I., Chemical nature of lubimin a new potato phytoalexin, DokladyAkademiaNauk. (SSSR) 200: 1470-1472 (1971).

[31] Murashige T. and Skoog F., A revised medium for rapid growth and bioassay with tobacco tissue cultures, Physiol. Plant.15: 473-497 (1962).

[32] Nagaoka T., Goto K., Watannabe A., Sakata Y. and Yoshihara T., Sesquiterpenoids in root exudates of Solanum aethiopicum. Zeitschrift für Naturforschung, Section C, Biosciences. 56: 707-713 (2001).

[33] Namdeo A.G., Investigation on pilot scale bioreactor with reference to the synthesis of bioactive compounds from cell suspension cultures of Catharanthus roseus Linn. Ph.D. Thesis, Devi AhilyaVishwaviyalaya Indore, M.P. India. (2004).

[34] Namdeo A.G., Patil S. and Fulzele D.P., Influence of fungal elicitors on production of ajmalicine by cell culture of Catharanthus roseus, Biotechnol Prog. 18: 159-162 (2002).

[35] Neshev G., Ivanova I. and Krusteva L. Response of different eggplant cultivars to Verticillium wilt (Verticillium dahliae kleb.), Acta Horticulturae 462 (119): 763-768 (1997).

[36] Pare P.W., Dmitrieva N. and Mabry T.J., Phytoalexin aurone induced in Cephalocereus senilis liquid suspension culture, Phytochem. 30: 1133-1135 (1991).

[37] Patel H. and Krishnamurthy R., Elicitors in plant tissue culture, J. of Pharmacognosy and Phytochemistry 2 (2): 60-65 (2013).

[38] Pegg G.F. and B. L. Brady, Verticillium Wilts. CABI Publishing, New York, USA, pp: 180-188 (2002).

[39] Preisig C.L. and Kuc J.A., Phytoalexins, elicitors, enhancers, suppresors, and other considerations in the regulation of R-gene resistance to Phytophthora infestans in potato. In: Molecular Determinants of Plant Disease (eds: S. Nishimura, C.P. Vance and N. Doke). Springer-Verlag, Berlin, Germany. pp 203-227 (1987).

[40] Ramakrishna S.U., Reddy G.R., Curtis W.R. and Humphrey A. Production of solavetivone by immobilized cells of Hyocyamus muticus, Biotechnol. Lett.15: 301-308 (1993). 
[41] SAS Institute, SAS Producers Guide, version 6. 3rd ed.: SAS Institute Inc.: Cary, NC. 705 p (1990).

[42] Saydam C. and Cöpçü M., Verticillium wilt in Ege Region and its importance on some vegetables, J. Turkish Phytopathol. 2: 34-40 (1973).

[43] Sbaghi M., Jeandet P., Faiure B., Bessis R. and Fournioux J.C., Developments of methods using phytoalexin (resveratrol) assessment as a selection criterion to screen grapevine in vitro cultures for resistance to grey mould (Botrytis cinera), Euphytica86: 41-47 (1995).

[44] Sevin M., Sevin N., Uslu Kıran S. and Ellialtıŏlu Ş., Determination of relation between resistance to Verticillium Dahliae Kleb. and phytoalexins accumulation in some Solanum species (in Turkish). Proceedings of the VIII. National Vegetable Growing Symposium, Van, Turkey. pp: 444-447 (2010).

[45] Stoessl A., Unwin C. H. and Ward E.W.B., Post infectional inhibitors from plants. I. Capsidiol an antifungal compound from Capsicum frutescens, Zeitschrift für Phytopathol. 74: 141-152 (1972).

[46] Stoessl A., Stothers J.B. and Ward E.W.B., The structure of some stress metabolites from Solanum melongena, Canadian J. Chem. 53: 3351-3358 (1975).

[47] Tjamos E.C. and Smith I.M., The role of phytoalexins in resistance of tomato to Verticillium wilt, Physiol. Plant Pathol. 4: 249-259 (1974).

[48] Tomiyama K., Sakuma T., Ishizaka N., Sato N., Katsui N., Takasugiand, M. and Masamune T., A new antifungal substance isolated from resistant potato tuber tissue infected by pathogens, Phytopathol.58: $115-116$ (1968).

[49] Uslu-Kiran S., Determination of relation between resistance to Verticillium dahliae and phytoalexins accumulation in various Solanum species by using callus suspension culture, Ph.D. Thesis, University of Ankara, Turkey, 112 pp (2004)

[50] Üstün, A. S., The physiological and biochemical investigation of the causes of the resistance to the root rot (Phytophtora capsici Leon.) disease in peppers. PhD Thesis, University of Ankara, Turkey, 121 pp (1990).

[51] Üstün, A. S. and Ercoskun A. T., Effect of some elicitors on the capsidiol amount in the fruit of peppers (Capsicum annuиm L.) having different sensitivities to root rot (Phytophthora capsici Leon.), Turkish J. Biol.18: 173-188 (1994).

[52] Üstün A. S., Çökmüş C. and Saçilik S. C., Accumulation of capsidiol in the pepper fruits (Capsicum annuиm L.) inoculated with some biotic elicitors, Turkish J. Agric. and For. 20: 431-438 (1996).

[53] Üstün A.S., Ellialtioğlu Ş., Mehmetoğlu Ü., Dolar F.S., Uslu-Kiran S. and Bayraktar H., Solanaceae familyası major fitoaleksinlerin hücre süspansiyon kültüründe üretilmesi, Ankara Üniversitesi Biyoteknoloji Projeleri, Proje No: 2002-42, Ankara, (in Turkish) 121 pp. (2006).

[54] Varns J. L., Kuc J. and Williams E. B., Terpenoid accumulation as a biochemical response of the potato tuber to Phytophthora infestans, Phytopathol. 61: 174-177 (1971).

[55] Ward E.W.B., Unwin C.H. and Stoessl A., Sesquiterpenoid phytoalexins from fruits of eggplants, Phytopathol.65: 859-863 (1975).

[56] Whitehead I.M., Threlfall D.R. and Ewing D.F., Cis-9, 10- dihydrocapsenone: a possible catabolite of capsidiol from cell suspension cultures of Capsicum annuиm, Phytochem. 28: 775-779 (1987).

[57] Yao M. K., Desilets H., Charles M.T., Boulanger R. and Tweddell R. J., Effect of mycorrhization on the accumulation of rishitin and solavetivone in potato plantlets challenged with Rhizoctonia solani, Mycorrhiza 13: 333-336 (2003).

[58] Yokose T., Katamoto K., Park S., Matsuura H. and Yoshihara T., Anti-fungal sesquiterpenoid from the root exudate of Solanum abutiloides, Biosci. Biotechnol. Biochem. 68: 2640-2642 (2004).

[59] Yoshihara T., Hagihara Y., Nagaoka T., Chiba S., Sakamura S., Fungitoxic compounds from the roots of the eggplant stock, Ann. Phytopath. Soc. Japan. 54: 453-459 (1988).

[60] Zhang W.W., Wang S.Z., Liu K., Si N., Qi F.J. and Jian G.J., Comparative expression analysis in susceptible and resistant Gossypium hirsutum responding to Verticillium dahliae infection by cDNAAFLP, Physiol. Mol. Plant Pathol. 80: 50-57 (2012).

Citation: S. Kiran et al., " Phytoalexin Accumulations in the Callus Culture of Two Eggplant Genotypes by using Verticillium dahliae Kleb. Elicitor", International Journal of Forestry and Horticulture(IJFH), vol. 3, no. 3, p.1-8, 2017. http://dx.doi.org/10.20431/2454-9487.0303001

Copyright: (๑) 2017 Authors. This is an open-access article distributed under the terms of the Creative Commons Attribution License, which permits unrestricted use, distribution, and reproduction in any medium, provided the original author and source are credited. 